SANDIA REPORT

SAND98-0418 • UC-901

Unlimited Release

Printed February 1998

RECEIVED

MAR 131998

OSTI

\title{
Demonstration of Real-Time Monitoring of a Photolithographic Exposure Process Using Chemical Ionization Mass Spectrometry
}

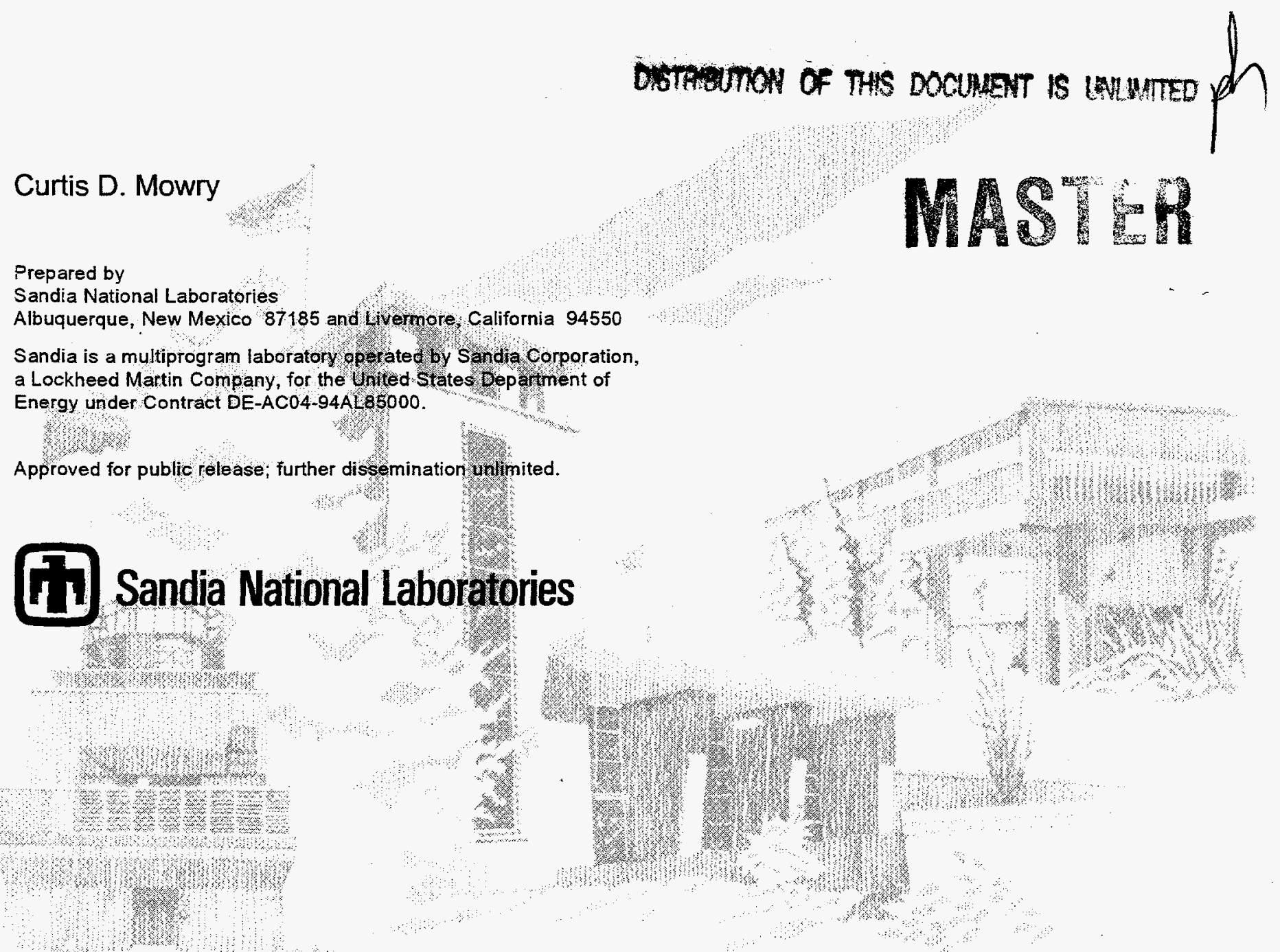


Issued by Sandia National Laboratories, operated for the United States Department of Energy by Sandia Corporation.

NOTICE: This report was prepared as an account of work sponsored by an agency of the United States Government. Neither the United States Government nor any agency thereof, nor any of their employees, nor any of their contractors, subcontractors, or their employees, makes any warranty, express or implied, or assumes any legal liability or responsibility for the accuracy, completeness, or usefulness of any information, apparatus, product, or process disclosed, or represents that its use would not infringe privately owned rights. Reference herein to any specific commercial product, process, or service by trade name, trademark, manufacturer, or otherwise, does not necessarily constitute or imply its endorsement, recommendation, or favoring by the United States Government, any agency thereof, or any of their contractors or subcontractors. The views and opinions expressed herein do not necessarily state or reflect those of the United States Government, any agency thereof, or any of their contractors.

Printed in the United States of America. This report has been reproduced directly from the best available copy.

Available to DOE and DOE contractors from Office of Scientific and Technical Information

P.O. Box 62

Oak Ridge, TN 37831

Prices available from (615) 576-8401, FTS 626-8401

Available to the public from

National Technical Information Service

U.S. Department of Commerce

5285 Port Royal Rd

Springfield, VA 22161

NTIS price codes

Printed copy: A03

Microfiche copy: $\mathrm{A} 01$

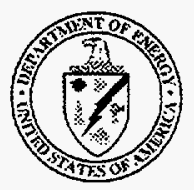




\section{DISCLAIMER}

Portions of this document may be illegible electronic image products. Images are produced from the best available original document. 


\title{
Demonstration of Real-Time Monitoring of a Photolithographic Exposure Process Using Chemical Ionization Mass Spectrometry
}

\author{
Curtis D. Mowry \\ Analytical Chemistry Department \\ Sandia National Laboratories \\ P.O. BOX 5800 \\ Albuquerque, NM 87185-0343
}

\begin{abstract}
Silicon wafers are coated with photoresist and exposed to ultraviolet (UV) light in a laboratory to simulate typical conditions expected in an actual semiconductor manufacturing process tool. Air is drawn through the exposure chamber and analyzed using chemical ionization mass spectrometry (Cl/MS). Species that evaporate or outgas from the wafer are thus detected. The purpose of such analyses is to determine the potential of $\mathrm{Cl} / \mathrm{MS}$ as a real-time process monitoring tool. Results demonstrate that $\mathrm{Cl} / \mathrm{MS}$ can remotely detect the products evolved before, during, and after wafer UV exposure; and that the quantity and type of products vary with the photoresist coated on the wafer. Such monitoring could provide semiconductor manufacturers benefits in quality control and process analysis. Tool and photoresist manufacturers could also realize benefits from this measurement technique with respect to new tool, method, or photoresist development. The benefits realized can lead to improved device yields and reduced product and development costs.
\end{abstract}




\section{Acknowledgments}

The author would like to thank Dianna Blair and Gerald Nelson, both from Sandia National Laboratories, for the use of the CI/MS instrument and spincoater, respectively. 


\section{Contents}

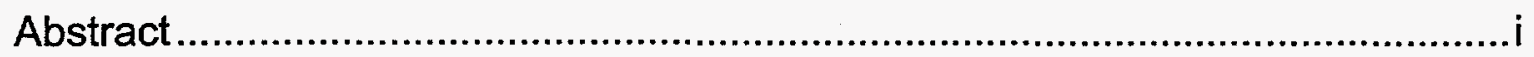

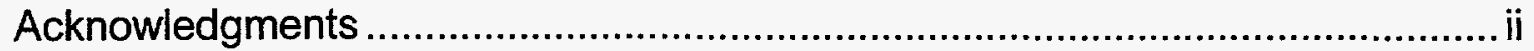

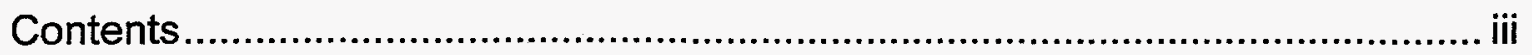

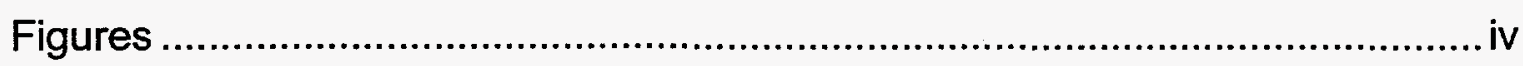

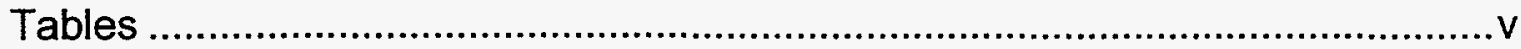

Acronyms and Abbreviations ................................................................ vi

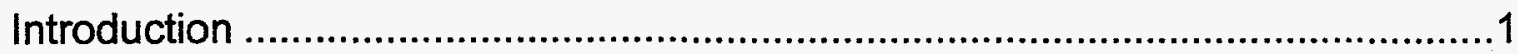

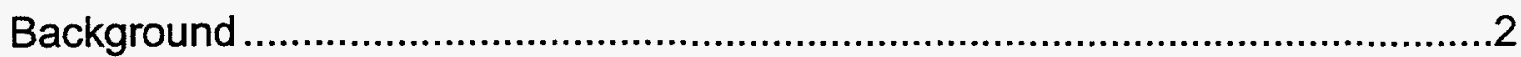

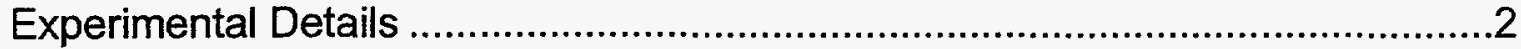

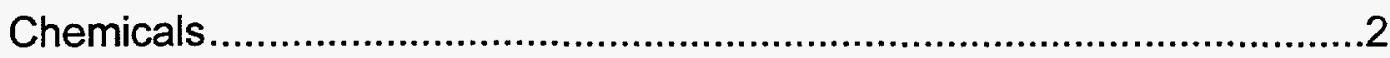

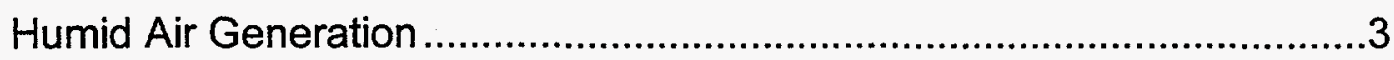

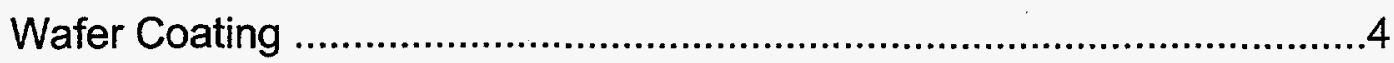

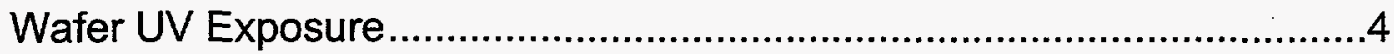

Chemical Ionization Mass Spectrometry ..............................................

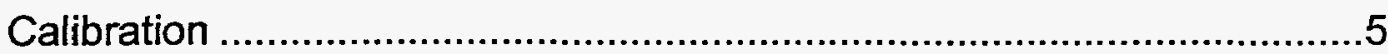

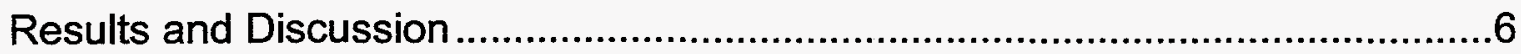

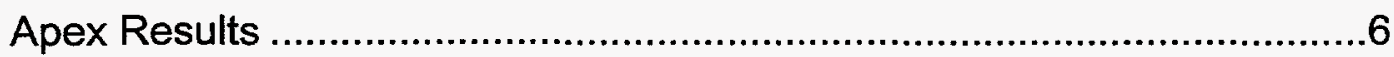

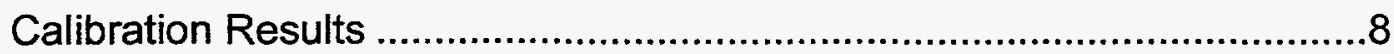

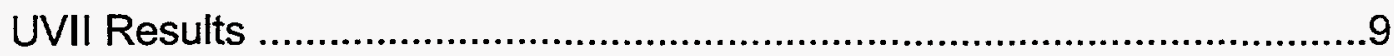

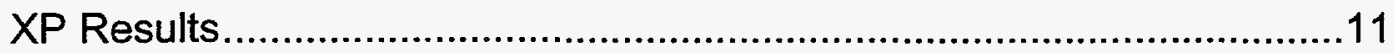

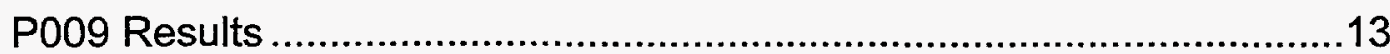

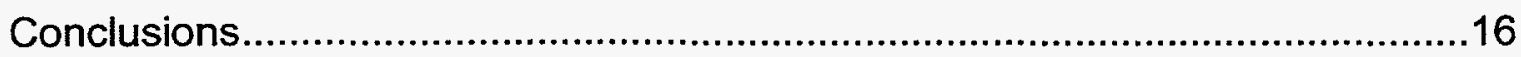




\section{Figures}

Figure 1: Apparatus for generating humid air..................................................

Figure 2: Chamber used for wafer UV light exposure .....................................5

Figure 3: Example mass spectrum (signal intensity vs. $\mathrm{m} / \mathrm{z}$ ) collected at peak (scan 785) of species outgassed from UV exposure of an Apex photoresist-coated wafer.

Figure 4: Selected ion plots ( $\mathrm{m} / \mathrm{z} 61,89,73,101)$ collected during "standard" exposure experiment, Apex-coated wafer (datafile L1218t01). The shaded area represents the time during which UV exposure occurred.

Figure 5: Selected ion plot ( $\mathrm{m} / \mathrm{z} 59)$ collected during instrument acetone calibration following an exposure experiment (datafile L1218T03).

Figure 6: Selected ion plots $(\mathrm{m} / \mathrm{z} 91,103,117,119)$ collected during the "standard" exposure experiment of a UVII-coated wafer (datafile L1218T04). The shaded area represents the time during which UV exposure occurred.

Figure 7: Selected ion plots $(\mathrm{m} / \mathrm{z} 91,103,119)$ collected during the "delayed" exposure experiment of a UVII-coated wafer (datafile L1218T05). The shaded area represents the time during which UV exposure occurred.

Figure 8: Selected ion plots $(\mathrm{m} / \mathrm{z} 91,103,117,119)$ collected during "standard" exposure experiment, XP-coated wafer (datafile L1218T07). The shaded area represents the time during which UV exposure occurred.

Figure 9: Selected ion plots ( $\mathrm{m} / \mathrm{z} 91,103,117,119)$ collected during "delayed" exposure experiment, XP-coated wafer (datafile L1218T08). The shaded area represents the time during which UV exposure occurred.

Figure 10: Selected ion plots $(\mathrm{m} / \mathrm{z} 63,65,73,89,91)$ collected during "standard" exposure experiment, P009-coated wafer (datafile L1218T03). The shaded area represents the time during which UV exposure occurred.

Figure 11: Selected ion plots $(\mathrm{m} / \mathrm{z} 63,65,73,89,91)$ collected during "delayed" exposure experiment, P009-coated wafer (datafile L1218T06). The shaded area represents the time during which UV exposure occurred. 


\section{Tables}

Table 1: Product list with manufacturer, product name, and acronyms..................3

Table 2: Primary ingredient listed on MSDS of each photoresist product, including CAS reference number.....................................................

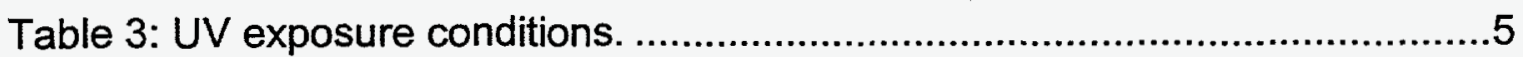




\section{Acronyms and Abbreviations}

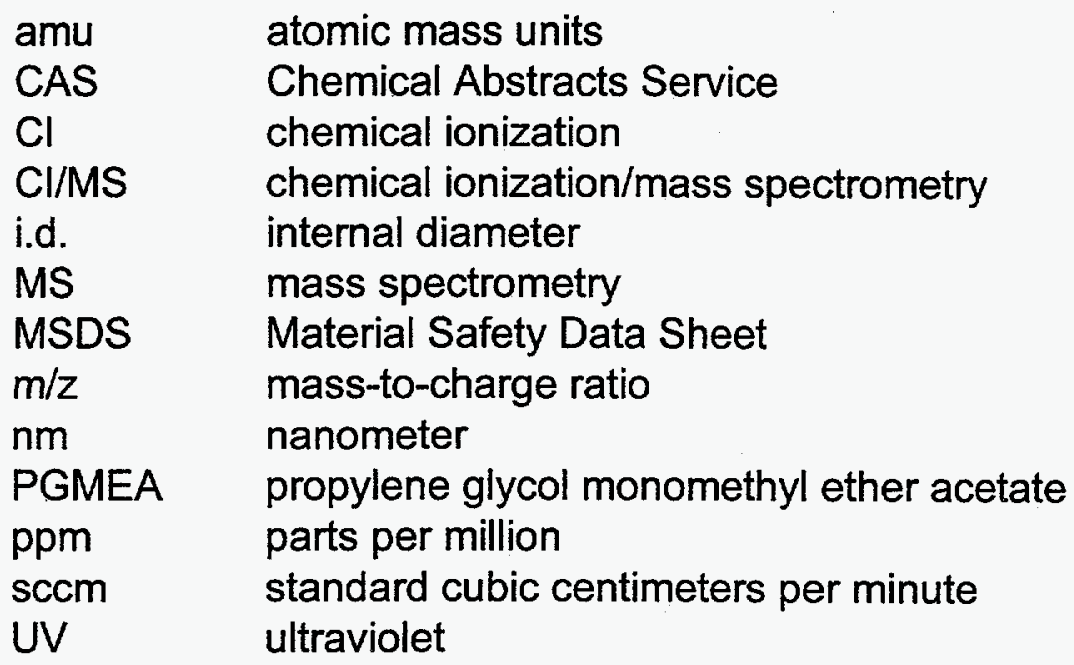




\section{Introduction}

The purpose of this work is to demonstrate the potential of chemical ionization mass spectrometry (Cl/MS) for real-time, in-situ monitoring of manufacturing processes within a semiconductor fabrication facility. More specifically, to demonstrate monitoring of the ultraviolet (UV) light exposure process during which patterns are imprinted on photoresist-coated silicon wafers. This report presents, for the first time, real-time analysis of species evolved from photoresist-coated silicon wafers before, during, and after UV light exposure. The wafers are prepared and illuminated under typical conditions that might be expected in actual semiconductor manufacturing facility processing tools.

Clean wafers are spin-coated with photoresist, soft-baked, cooled in an exposure chamber, and then exposed to UV light. While inside the chamber, air is passed over the wafer and introduced into the mass spectrometer for analysis. Qualitative detection of outgassed species from wafers coated with photoresist before, during, and after UV light exposure is demonstrated. Acetone calibrations illustrate the capability to perform quantitative analysis of target analytes. Four commercially available photoresists are tested individually. The primary component listed on the Material Safety Data Sheet (MSDS) of each photoresist tested is identified in the outgassed products following UV exposure. Additional species of unknown origin are also detected. For some resists, detection of ions prior to UV exposure suggests evaporation of certain species. Further knowledge of photoresist composition and photochemistry would be required to identify these species.

Current process metrics for UV exposure are determined by off-line measurement techniques. During exposure, tool parameters are monitored, yet these monitors cannot provide information on the processes occurring on the wafer surface or even the status of the wafer. Cl/MS monitoring, however, can provide this information and therefore be useful to tool and photoresist manufacturers in the development of new tool, method, or photoresist development.

Monitoring of the UV exposure process will also be of interest to semiconductor manufacturers. The signals detected in these experiments, which are in-situ and real-time, could be utilized for process monitoring functions by semiconductor manufacturers. These functions include fault detection, quality control, and failure analysis. In addition, the measurements are taken remotely, demonstrating that the monitor need not be located in the clean room environment. This allows more flexibility in the actual on-site utilization of this measurement technology. 
This report is divided into four sections: background, experimental details, results and discussion, and conclusions.

\section{Background}

The semiconductor industry uses photolithography or "printing with light" to produce features such as resistors, capacitors, and transistors within a semiconductor device. Light sensitive chemicals are coated and exposed to UV light to create the layers required. These light sensitive chemicals are called photoresists and contain mixtures of solvents, polymer building blocks, and other reactive substances. To obtain the small physical size of the features, the UV light must be focused to micron or sub-micron dimensions. The pattern to be etched on the photoresist layer is created on a template called a reticle, through which the UV light is passed. The reticle is protected by a quartz window called a pellicle.

The quality of the pattern imaged onto the wafer degrades if the pellicle becomes dirty or if dust particles adhere to surface. Species that evolve as UV light interacts with the photoresist mixture can be estimated based on factors such as photoresist composition and the photochemistry of photoresist components. The volatility of components and photochemical products is also a factor. The products that evolve, however, have not been measured by any analytical technique. Cl/MS has the ability to measure (qualitatively or quantitatively) any photodegradation products, solvent molecules, or unreacted monomers that evolve or outgas from the wafer surface to the surrounding area.

\section{Experimental Details}

\section{Chemicals}

All chemicals related to semiconductor manufacturing were used as received. Manufacturers of photoresists include Shipley (Marlborough, Massachusetts) and Tokyo Ohka Kogyo Co., Ltd. (Tokyo, Japan). The specific photoresist products used are listed in Table 1 with the acronyms used in this document. The MSDS for each product lists several ingredients with specified or unspecified concentrations. The primary ingredient, or the ingredient with the highest MSDS-listed concentration, for each product is listed in Table 2 along with the Chemical Abstracts Service (CAS) reference number for that compound. Acetone (Fisher Scientific, Pittsburgh, Pennsylvania, HPLC grade) was used as received. 
Table 1: Product list with manufacturer, product name, and acronyms.

\begin{tabular}{|c|c|c|}
\hline Manufacturer & Product & Product Acronym \\
\hline Shipley & Apex-E 2408-L Photo Resist & Apex \\
\hline Shipley & $\begin{array}{c}\text { UVII HS-0.8 Photo Resist } \\
\text { (XP-9549Z-0.8) }\end{array}$ & UVII \\
\hline Shipley & $\begin{array}{c}\text { Positive DUV Photo Resist } \\
\text { XP-96569 }\end{array}$ & XP \\
\hline Tokyo Ohka Kogyo & TDVR-P009 FS PM & P009 \\
\hline
\end{tabular}

Table 2: Primary ingredient listed on MSDS of each photoresist product, including CAS reference number.

\begin{tabular}{|c|c|c|}
\hline Product Acronym & Primary Ingredient & CAS \# \\
\hline Apex & $\begin{array}{c}\text { propylene glycol monomethyl } \\
\text { ether acetate }\end{array}$ & $108-65-6$ \\
\hline UVII & ethyl lactate & $97-64-3$ \\
\hline XP & ethyl lactate & $97-64-3$ \\
\hline P009 & $\begin{array}{c}\text { propylene glycol monomethyl } \\
\text { ether acetate }\end{array}$ & $108-65-6$ \\
\hline
\end{tabular}

\section{Humid Air Generation}

Air supplied to the exposure chamber was humidified using the apparatus shown in Figure 1. Room air was passed over a heated water reservoir and through a hygrometer (HyCal Sensing, El Monte, California). Target relative humidity ranged from 35 to 40 percent. Because the exposure chamber was repeatedly opened and closed, however, a constant air flow was not maintained and therefore a constant humidity value was not possible. The humidity remained above 35 percent in all experiments and sometimes reached values near 100 percent. The initial humidity was typically higher, dropping over the period of each experiment. 


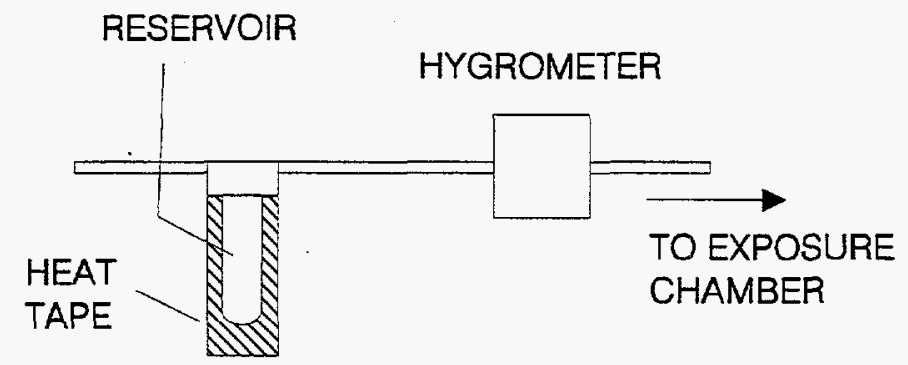

Figure 1: Apparatus for generating humid air.

\section{Wafer Coating}

For each photoresist, a clean four-inch diameter wafer was spin-coated at 3700 rpm for 10 seconds using a spin-coater (Headway Research, Inc., Garland, Texas, model 1-EC101D-R485). Photoresist ( $2.5 \mathrm{cc}$ ) was applied using a digital pipette (Rainin Instruments, Woburn, Massachusetts, model EDP-plus) during the first second of spin. Following spin-coat, each wafer was baked at $90^{\circ} \mathrm{C}$ $\left( \pm 2^{\circ} \mathrm{C}\right.$ ) for 90 seconds in a ventilation hood on a heated block (Fisher Scientific, cat. no. 11-718). The wafer was then placed into the exposure chamber to cool for 2 minutes at ambient temperature prior to exposure. The chamber was sealed during cooling.

A single wafer, cleaned between individual experiments, was utilized for all experiments. The cleaning procedure consisted of applying acetone several times to the wafer while spinning on the spin-coater. The wafer was baked for greater than 10 minutes and cooled to ambient before re-use.

\section{Wafer UV Exposure}

The exposure chamber illustrated in Figure 2 was constructed from standard six-inch outer diameter conflat (copper gasket sealed) flanges (MDC Vacuum Products Corp., Hayward, California). These include a zero-profile quartz viewport flange, a double-sided flange with opposing threaded ports, and a blank flange. Pipethread to $1 / 4$ " swagelok adapters were added to the flanges. UV light supplied by a 1000-watt mercury lamp was reflected by a $260-320 \mathrm{~nm}$ dicroic mirror and focused with a $75 \mathrm{~mm}$ focal point lens (Oriel, Stratford, Connecticut, part numbers 66024,66227 , and 41750 respectively). Prior to focusing, the light was filtered using a $248 \mathrm{~nm}$ bandpass filter (Acton Research Crop, Acton, Massachusetts, part no. 248-N-2D, 22.7 nm FWHM, 22.3\% transmission) The focused beam was scanned over the surface of the wafer using an $x$-translation stage and manual movement in the $y$-direction after each pass across the wafer. Exposure conditions are listed in Table 3. 


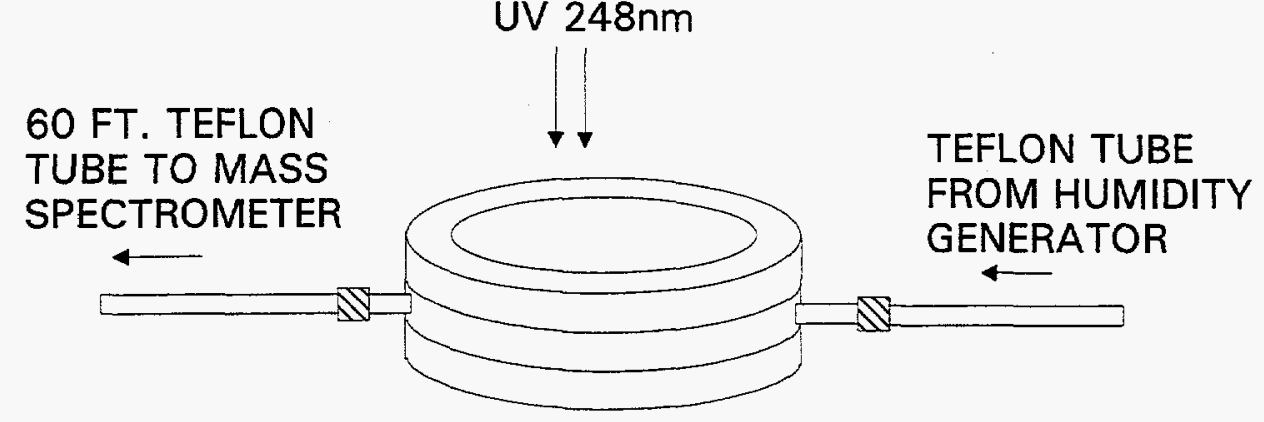

Figure 2: Chamber used for wafer UV light exposure.

Table 3: UV exposure conditions.

\begin{tabular}{ll|}
\hline Measured UV power: & $60 \mathrm{~mW}$ \\
Measured illumination area: & $0.71 \mathrm{~cm}^{2}$ \\
Approximate scan rate: & $0.4 \mathrm{~cm} / \mathrm{sec}$. \\
Approximate volume of chamber: & $250 \mathrm{~cm}^{3}$ \\
Airflow rate through chamber: & $2000 \mathrm{cc} / \mathrm{min}$. \\
\hline
\end{tabular}

\section{Chemical lonization Mass Spectrometry}

The sampling line from the exposure chamber was connected to the mass spectrometer using a custom sampling manifold designed at Sandia National Laboratories. A constant flow of $2000 \mathrm{sccm}$ (standard cubic centimeters per minute) was drawn from the exposure chamber. Pressure within the sampling manifold was kept constant at 200 torr. Vacuum was supplied by a direct-drive mechanical pump (Alcatel Vacuum Products Inc., Hingham, Massachusetts, type 2004).

$\mathrm{Cl} / \mathrm{MS}$ was performed using an INCOS XL mass spectrometer (Finnigan Corp., San Jose, California). The instrument scanned a mass range of 50-175 amu at the rate of one scan per 0.8276 seconds. Source and transfer line temperatures were set at $120^{\circ} \mathrm{C}$ and $100^{\circ} \mathrm{C}$ respectively. Methane was the $\mathrm{Cl}$ reagent gas.

\section{Calibration}

Calibration of the INCOS mass spectrometer was achieved using an acetone permeation tube (VTI, Oak Ridge, Tennessee, model LPL-5-ACE$4 \mathrm{MVCR}-\mathrm{FV}-\mathrm{FTV}$ ). At a given temperature and airflow, a constant concentration of acetone is achieved. Calibration was performed at the end of each exposure experiment, without interruption of the sampling flow from the exposure chamber. 


\section{Results and Discussion}

The following presents data obtained after the silicon wafer was coated with a particular photoresist, soft-baked, and placed in the exposure chamber to $\mathrm{cool}$ as detailed in the experimental section. While the wafer cooled, the chamber was sealed so that humid air was swept through the chamber and introduced to the mass spectrometer. Full mass spectral scans (mass range 50 to $175 \mathrm{amu}$ ) were collected during wafer cooling and chamber sealing. An example of a single scan is shown in Figure 3 , which plots signal intensity versus mass-to-charge ratio $(\mathrm{m} / \mathrm{z})$.

Because each chemical species detected has its own mass spectral "fingerprint", the scan shown in Figure 3 can be thought of as a combination of several fingerprints. Chemical ionization reduces the complexity of these patterns which reduces signal overlap and simplifies spectral interpretation. Individual ion signals observed to vary in intensity during the course of an experiment are plotted versus scan number. This is called a selected ion plot (see Figure 4). In this report, each ion signal plotted is individually normalized for ease of viewing.

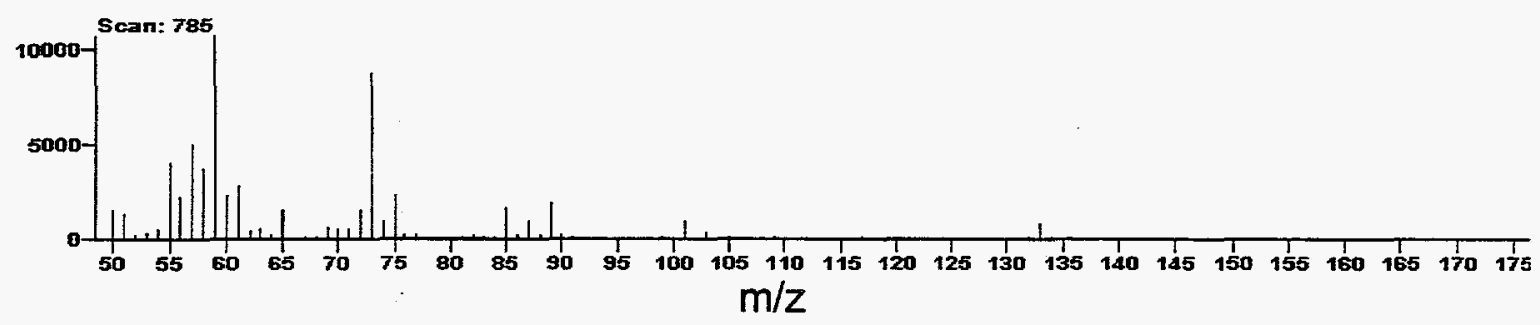

Figure 3: Example mass spectrum (signal intensity vs. $\mathrm{m} / \mathrm{z}$ ) collected at peak (scan 785 ) of species outgassed from UV exposure of an Apex photoresist-coated wafer.

Two experiments were performed for each photoresist; a "standard" exposure and a "delayed" exposure. In the "standard" exposure experiment the wafer was cooled for 2 minutes prior to UV light exposure. This represents a typical wafer cooling period. In the "delayed" exposure, a longer cooling period was allowed. This determined if the signals detected were a result of the UV exposure or simply evaporation. All selected ion plots shown below plot signals from the point in time at which the chamber was fully sealed.

\section{Apex Results}

Individual ion signals collected during remote real-time monitoring of a "standard" exposure experiment are plotted in Figure 4 as normalized signal intensity versus scan number. Only those signals that varied with exposure are shown. The shaded area represents the time during which UV exposure occurred. In Figure 4 the ion signals at $\mathrm{m} / \mathrm{z} 73$ and 101 represent fragment ions of propylene glycol monomethyl ether acetate (PGMEA), the primary ingredient 
listed on the MSDS for Apex (see Table 2). The protonated molecular ion of PGMEA was also observed at $\mathrm{m} / \mathrm{z} 133$.

The identity of the ions at $\mathrm{m} / \mathrm{z} 61$ and 89 are not known and may be either photoproducts or photoresist components. Additionally, they may be fragment ions (as $\mathrm{m} / \mathrm{z} 73$ is for PGMEA) or protonated molecular ions (as $\mathrm{m} / \mathrm{z} 133$ is for PGMEA) of outgassed species. Further knowledge of the photoresist composition or photochemistry upon UV exposure would be required to determine the origin of these ions. Precise knowledge of their identities, however, would not be required for their signal(s) to be used for process diagnostics.

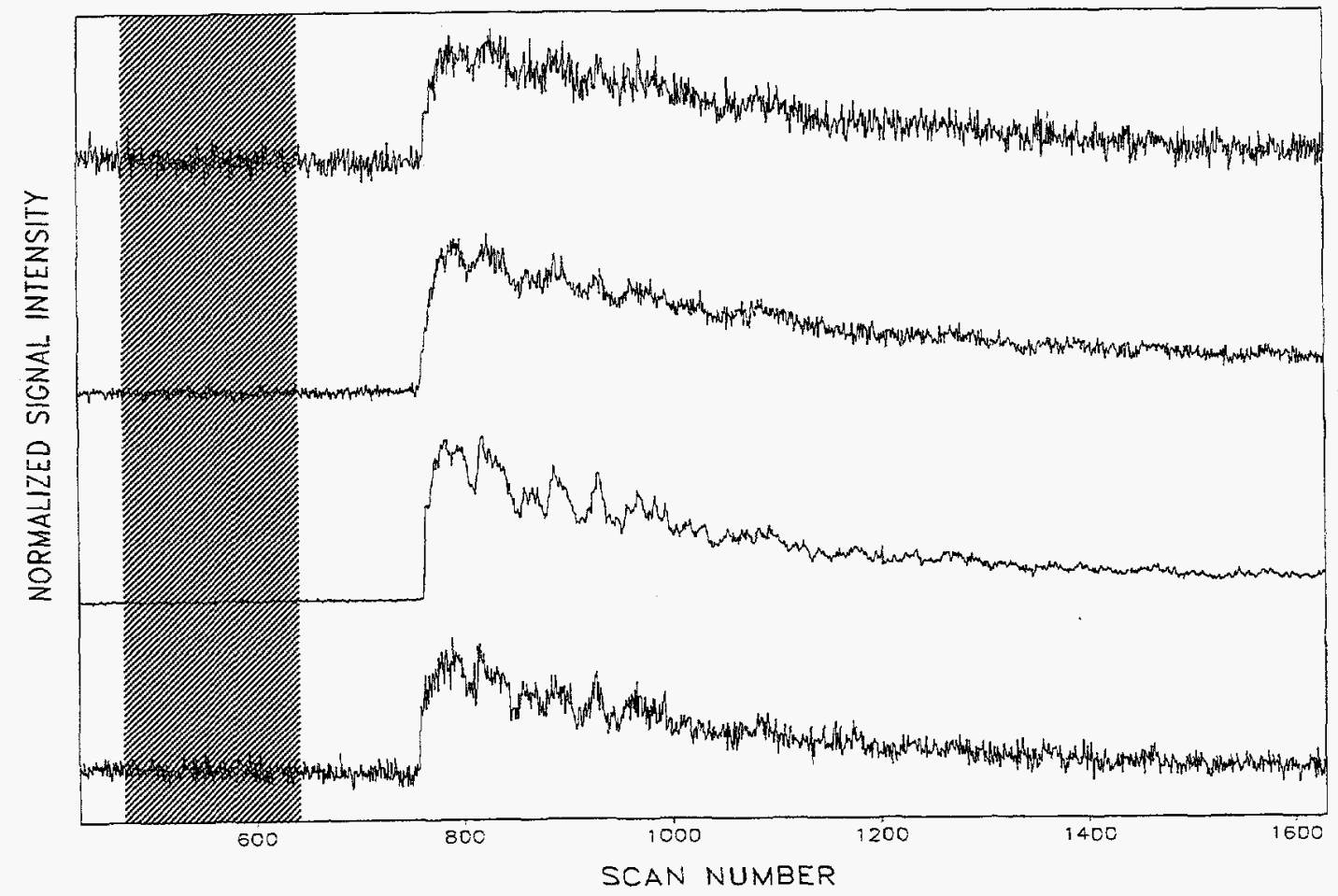

Figure 4: Selected ion plots ( $\mathrm{m} / \mathrm{z} 61,89,73,101)$ collected during "standard" exposure experiment, Apex-coated wafer (datafile L1218t01). The shaded area represents the time during which UV exposure occurred.

The delay time between the start of exposure and the start of the signal increase in Figure 4 was expected to be on the order of a few seconds based on the sampling line internal diameter, length, and airflow rate. The signal response, however, was delayed by approximately 3.7 minutes. The extra delay may be caused by the low volatility of PGMEA or some other transport phenomenon; but could also be a delayed response in the photochemical reaction on the wafer surface. The responsible factor is not known, however experiments with shorter sampling lines could eliminate any instrumental causes. Despite this uncertainty, the fact that useful signals can be obtained at a remote location through a long sampling line has been demonstrated. 
A "delayed" exposure experiment was performed to determine whether the signal(s) previously observed were a result of the UV exposure, evaporation, or an artifact created by the sampling configuration. A coated wafer was placed into the exposure chamber and was not exposed for several minutes. Prior to exposure, signal changes were not observed at any $\mathrm{m} / \mathrm{z}$. The signals observed in the previous experiment (see Figure 4), therefore, were a direct result of the UV exposure.

Monitoring continued for 8 minutes, at which time UV exposure proceeded as in the previous experiment. In effect, this wafer had approximately 8 minutes of cooling (at room temperature) rather than the "standard" 2 minutes. Signal changes were not observed during or following UV exposure. UV exposure in this case, therefore, did not cause any outgassing from the wafer above the detection limits of the instrument. An acetone calibration (see also Calibration Results) at the end of the experiment confirmed that the instrument was functioning properly.

A discussion regarding the factors that could cause the lack of outgassed products in the "delayed" exposure experiment is beyond the scope of this report. The point relevant to this demonstration is that the process was monitored remotely and in real-time, and the signals detected allowed differentiation between a wafer cooled for 2 minutes and one cooled for 8 minutes.

\section{Calibration Results}

As described in the experimental section, the instrument was calibrated at the end of each experiment. Figure 5 plots the signal obtained for an acetone calibration produced by seeding the instrument sampling flow with $0.22 \mathrm{ppm}$ of acetone at the end of an exposure experiment. The monitored ion signal represents the protonated molecular ion $(\mathrm{m} / \mathrm{z} 59)$ of acetone. The baselinesubtracted peak height is 35,700 units, roughly demonstrating the detection limits of the instrumentation.

The instrument will have a different sensitivity factor for each compound detected, yet quantitation is possible with individual calibration standards. Another approach is to use the acetone signal as the method for comparing results from different instruments or the same instrument on different occasions. Large variations in the instrument's acetone response during these experiments were observed, however the cause was believed to be the intermittent nature in which the permeation tube was used here. The permeation tube was designed to have a constant flow for long periods of time. 
Calibration sources are available for a wide variety of compounds and can be custom-built. This would allow quantitative analysis, if desired, for any target analyte of interest. For the general purpose of process monitoring, verification or qualification of instrument sensitivity would require only a single calibrant source.

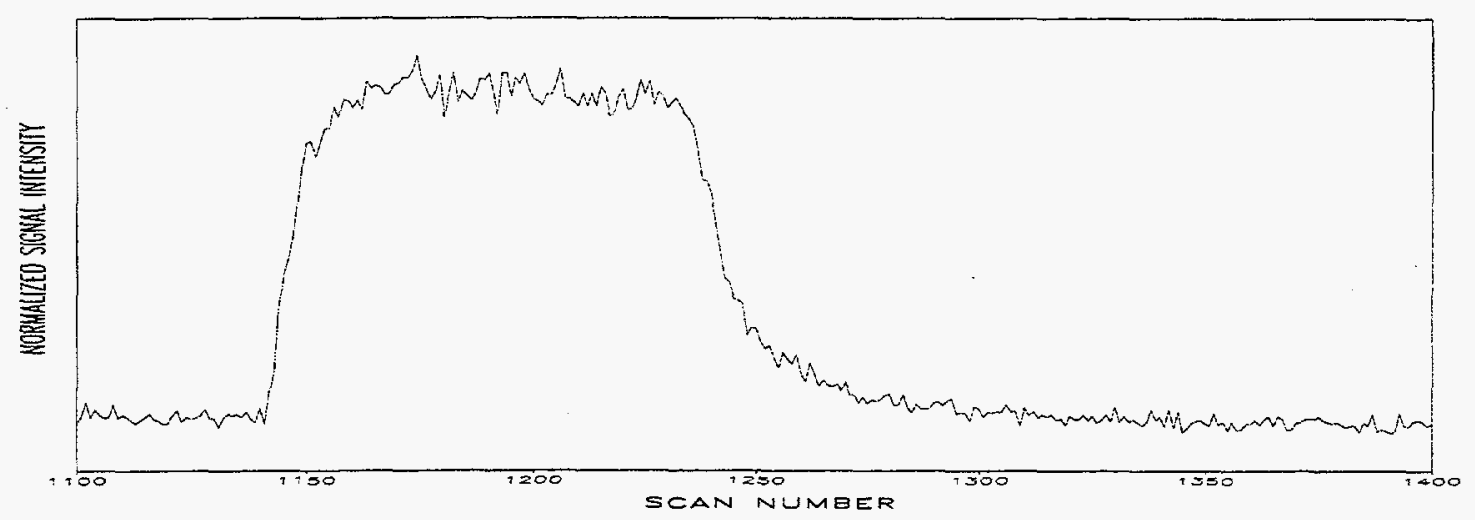

Figure 5: Selected ion plot $(\mathrm{m} / \mathrm{z} 59)$ collected during instrument acetone calibration following an exposure experiment (datafile L1218T03).

\section{UVII Results}

Figure 6 illustrates real-time monitoring of the exposure chamber before, during, and after UV exposure of a UVII photoresist-coated wafer. This wafer had a "standard" 2-minute cooling time before exposure. The shaded area indicates the time at which exposure occurred. The delay between the start of exposure and the start of the increased signal level was on the order of a few seconds, as expected. Individual ion signals for $\mathrm{m} / \mathrm{z}$ values $91,103,117$, and 119 are individually normalized and plotted versus scan number. Variation in other ion signals was not observed.

The ion signals observed are specific to the chemical species detected, and because UVII and Apex have different primary ingredients (as shown on their MSDS's), different ion signals would be expected. Differences or similarities in the photochemical products of each resist system would also be reflected in the $\mathrm{m} / \mathrm{z}$ values observed, within the detection limits and scan range limitations of the instrument.

For UVII, the signals at $\mathrm{m} / \mathrm{z} 119,103$, and 91 are likely due to ethyl lactate, the primary ingredient listed on the MSDS (see Table 2). The protonated molecular ion of ethyl lactate resulting from chemical ionization would be expected at $\mathrm{m} / \mathrm{z} 119$. The signal at $\mathrm{m} / \mathrm{z} 117$ may represent either a photoproduct of UV exposure or another photoresist component. 


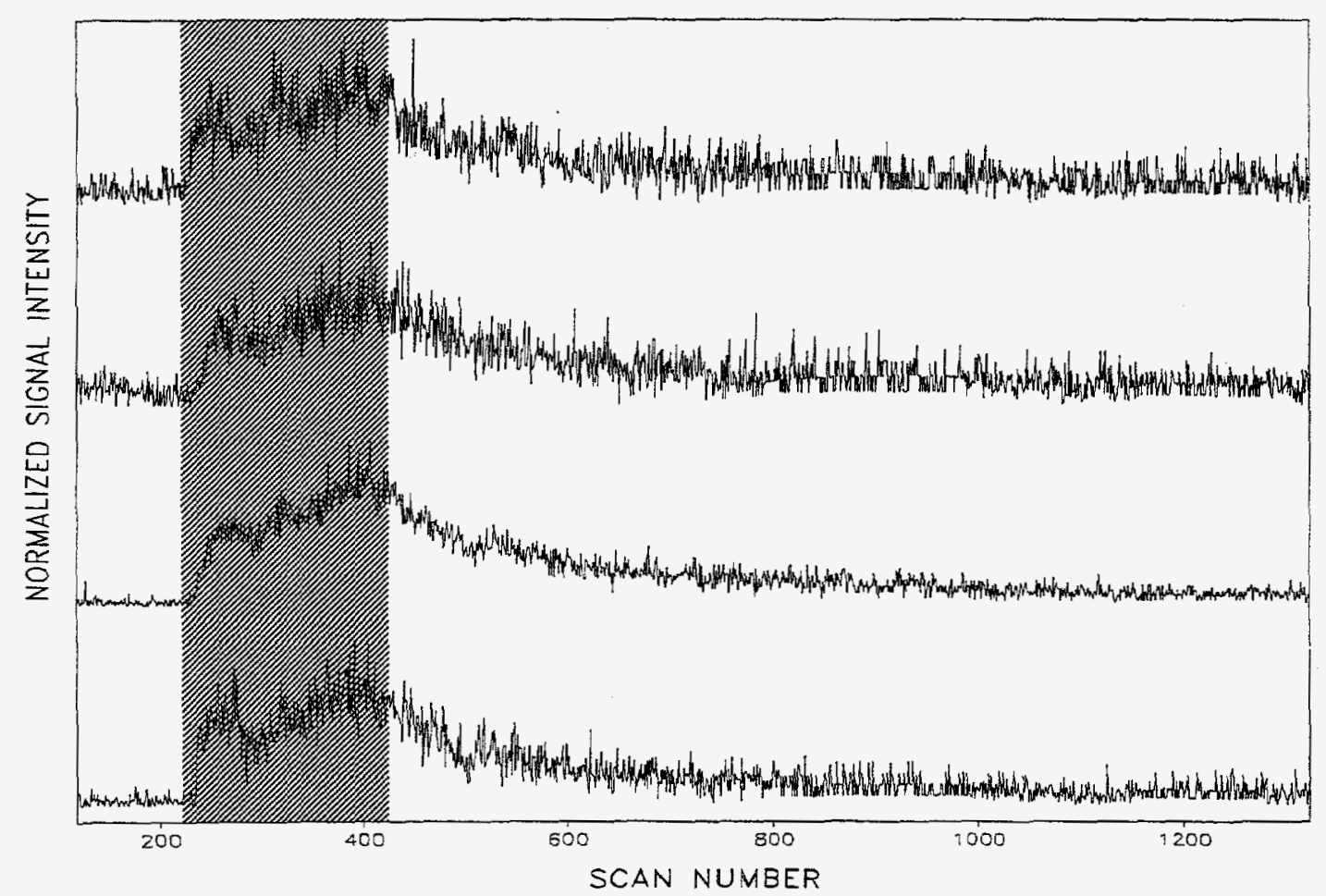

Figure 6: Selected ion plots ( $\mathrm{m} / \mathrm{z} 91,103,117,119)$ collected during the "standard" exposure experiment of a UVII-coated wafer (datafile L1218T04). The shaded area represents the time during which UV exposure occurred.

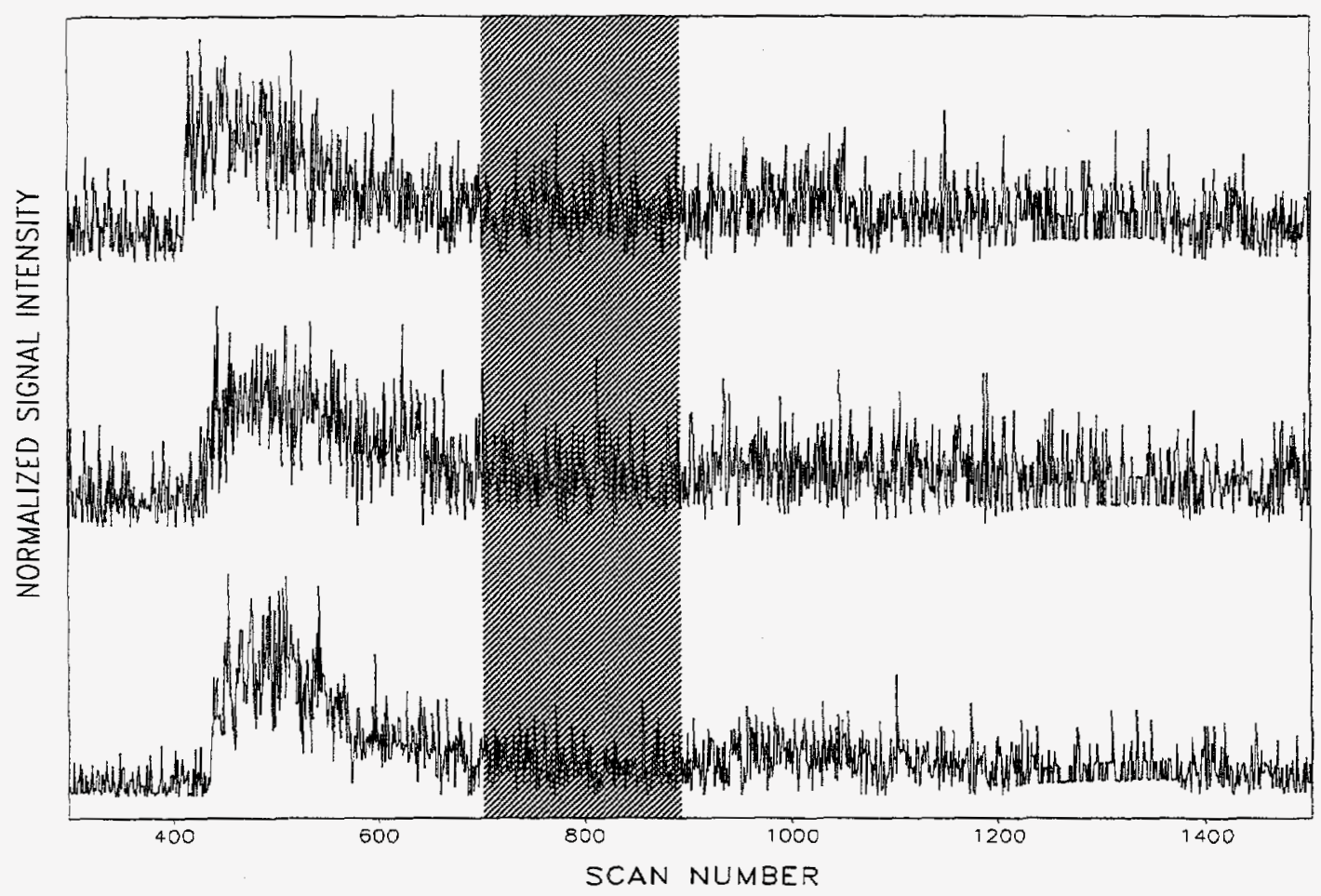

Figure 7: Selected ion plots $(\mathrm{m} / \mathrm{z}$ 91, 103, 119) collected during the "delayed" exposure experiment of a UVII-coated wafer (datafile L1218T05). The shaded area represents the time during which UV exposure occurred. 
Results of the "delayed" exposure experiment, representing a 10-minute cooling time for a UVII photoresist-coated wafer, are shown in Figure 7. Small changes were observed for the ions at $\mathrm{m} / \mathrm{z} 91,103$, and 119 prior to exposure, suggesting that some ethyl lactate evaporates from the wafer during cooling. Evaporation of the species observed at $\mathrm{m} / \mathrm{z} 117$ in the "standard" exposure experiment was not observed. Changes in signal intensity during or following exposure were not observed at any $\mathrm{m} / \mathrm{z}$.

Although some ethyl lactate evaporation was observed in the "delayed" exposure experiment, about twice the signal level of ethyl lactate was detected in the "standard" exposure experiment, suggesting that UV exposure generates vapor phase ethyl lactate. The results demonstrate that $\mathrm{Cl} / \mathrm{MS}$ is sensitive enough to detect exposure products and also components that are simply evaporating off the wafer surface.

\section{XP Results}

Results similar to those for UVII photoresist-coated wafers were observed for XP photoresist-coated wafers in both the "standard" and "delayed" exposure experiments. Figure 8 plots the ion signals that varied during the "standard" exposure experiment, in which the wafer was cooled for 2 minutes prior to UV exposure (indicated by the shaded area). Two species, ethyl lactate $(\mathrm{m} / \mathrm{z} 91$, 103 , and 119), the primary ingredient listed on the MSDS for XP (see Table 2), and an unknown species at $\mathrm{m} / \mathrm{z} 117$ were detected (see Figure 8). No other ion signals were observed to vary.

In the "delayed" exposure experiment (Figure 9), some evaporation of ethyl lactate and $\mathrm{m} / \mathrm{z} 117$ was detected prior to exposure. The signal intensity for each ion in Figure 9 is about half as intense as was observed in the "standard" exposure experiment. Remote monitoring with Cl/MS was capable of detecting the effects of exposure.

After the extended cooling time (at ambient temperature) of approximately 10 minutes, the wafer was exposed (shaded area of Figure 9) while monitoring continued. There was no observed signal increase for the ions in Figure 9 during or after UV exposure, nor was there any observed signal increase in other ions monitored by the instrument, which scanned a range from 50 to $175 \mathrm{amu}$. This exposure, therefore, had no detectable effect on the wafer. 


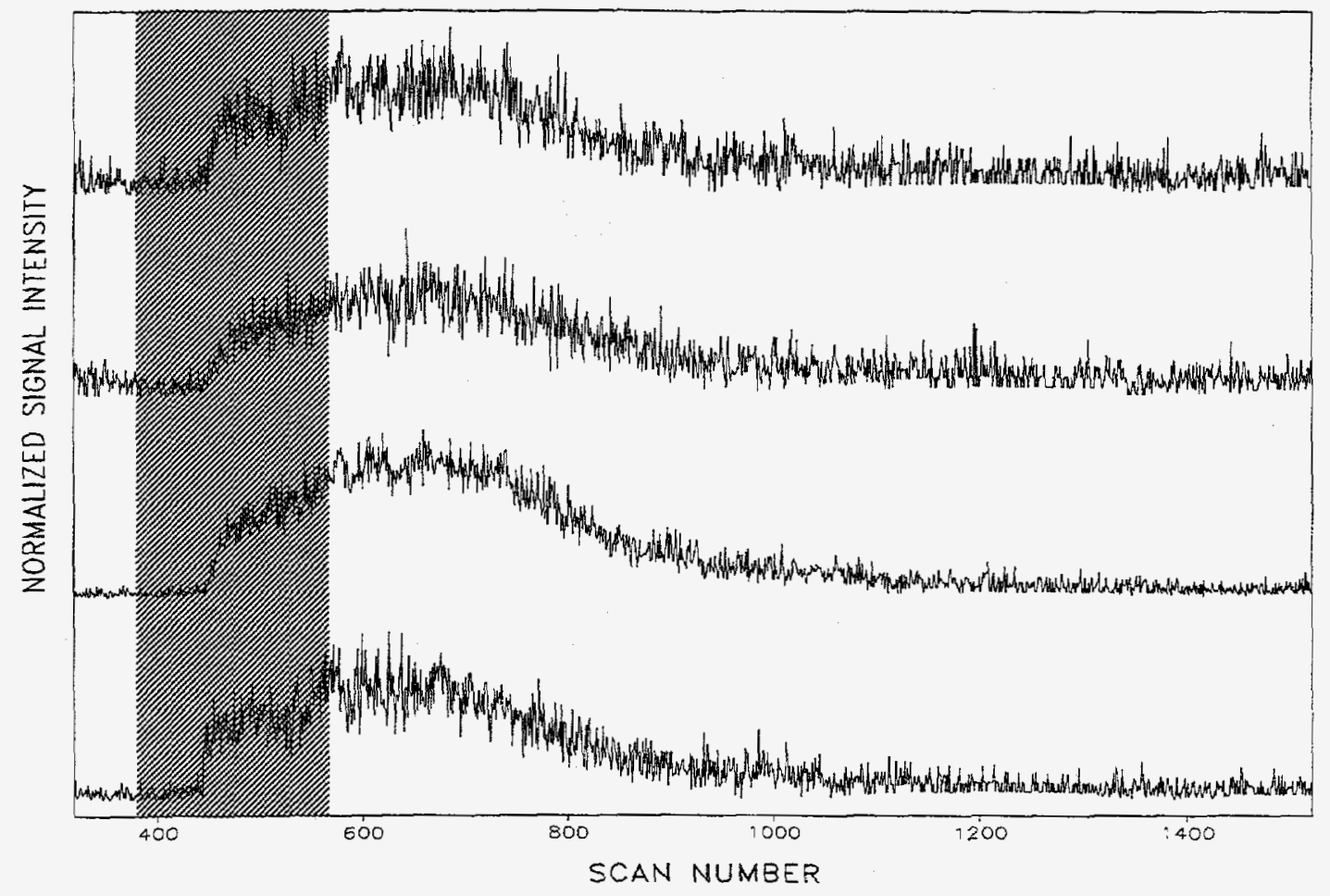

Figure 8: Selected ion plots (m/z 91, 103, 117, 119) collected during "standard" exposure experiment, XP-coated wafer (datafile L1218T07). The shaded area represents the time during which UV exposure occurred.

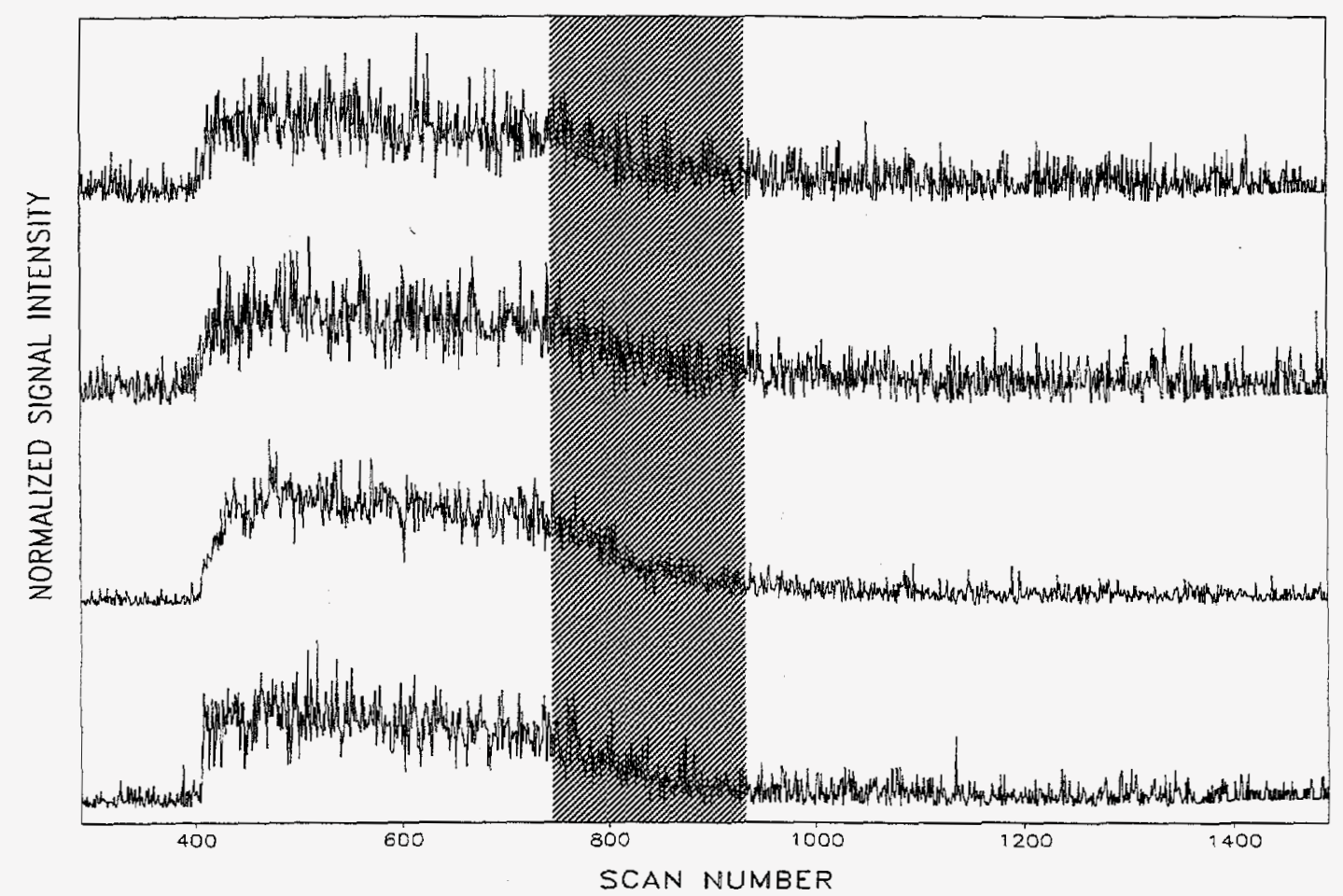

Figure 9: Selected ion plots $(\mathrm{m} / \mathbf{z} 91,103,117,119)$ collected during "delayed" exposure experiment, XP-coated wafer (datafile L1218T08). The shaded area represents the time during which UV exposure occurred. 


\section{P009 Results}

Some of the ion signals that varied during the "standard" exposure experiment are plotted in Figure 10 as normalized signal intensity versus scan number. The shaded area represents the time during which UV exposure occurred. Large increases in $\mathrm{m} / \mathrm{z} 61$ (not plotted), 63, and 65, and a smaller increase in $\mathrm{m} / \mathrm{z} 91$ were detected (see Figure 10) immediately after exposure. It is not known whether these signals represent molecular species or fragments. The dip at the peak of the ion signal was likely caused by a pause in the exposure process, as the exposure chamber had to be manually moved in the $y$ direction.

The ion signal at $\mathrm{m} / \mathrm{z} 73$ shown in Figure 10 represents propylene glycol monomethyl ether acetate (PGMEA), the primary ingredient listed on the MSDS for P009 (see Table 2). The molecular ion of PGMEA (m/z 133) and a fragment ( $\mathrm{m} / \mathrm{z}$ 101) were also observed. The PGMEA signal increased approximately 4.5 minutes after exposure, in contrast to those that increased even before exposure was completed. Different response times may be expected between compounds with large differences in volatility; however, 4.5 minutes is significantly longer than expected.

A similar delay in ion signals associated with PGMEA was observed during monitoring of an Apex-coated wafer (see Apex Results). This could suggest an instrumental or sampling effect strictly associated with PGMEA, however it is believed that these factors would not produce the sharp signal increase that is observed. Since both Apex and P009 list PGMEA as the primary ingredient on their MSDS's, the PGMEA signal delay suggests a chemical process(es) occurring some time after exposure. This process(es) may be related to photochemical or physical changes in the photoresist.

The detection of $\mathrm{m} / \mathrm{z} 89$ immediately after exposure and then again later at the same time that PGMEA signal rises also suggests a chemical process occurring several minutes after exposure. The early signal increase and the late signal increase may, however, represent two different species or fragments of different species. A delayed rise in $\mathrm{m} / \mathrm{z} 89$ was also observed for Apex (see Apex Results), suggesting that $\mathrm{m} / \mathrm{z} 89$ is related to PGMEA and more importantly supporting the hypothesis that the delay is caused by a wafer condition rather than the procedures or instrumentation. Because changes in chamber humidity or sampling effects cannot be ruled out the cause, however, experiments with improved humidity control and short sampling lines are recommended. More knowledge of the specific photoresist compositions and reactivities would also be required to determine the cause(s) of the PGMEA and $\mathrm{m} / \mathrm{z} 89$ ion signal delays.

A "delayed" exposure experiment was performed to determine if UV exposure was responsible for the species detected or if they had simply 
evaporated from the wafer. The wafer was cooled (at ambient temperature) for almost 10 minutes prior to UV exposure. The chamber was monitored by Cl/MS continuously. The results of this experiment are shown in Figure 11, plotted as before. Outgassed products were not detected until after UV exposure commenced.

Based upon peak height, similar quantities of $\mathrm{m} / \mathrm{z} 61,63,65,89$, and 91 were detected in the "standard" and "delayed" experiments following exposure. The PGMEA signal ( $\mathrm{m} / \mathrm{z} 73$ ) in the "delayed" exposure experiment (Figure 11), however, was smaller than that observed in the "standard" exposure experiment (Figure 10). There are several factors that could be responsible for the difference including differences in humidity or wafer processing variables. More importantly, the PGMEA increase was observed only after a delay of almost 10 minutes in both experiments.

In both exposure experiments using P009, remote monitoring using $\mathrm{Cl} / \mathrm{MS}$ detected several signals that could serve as process indicators. 


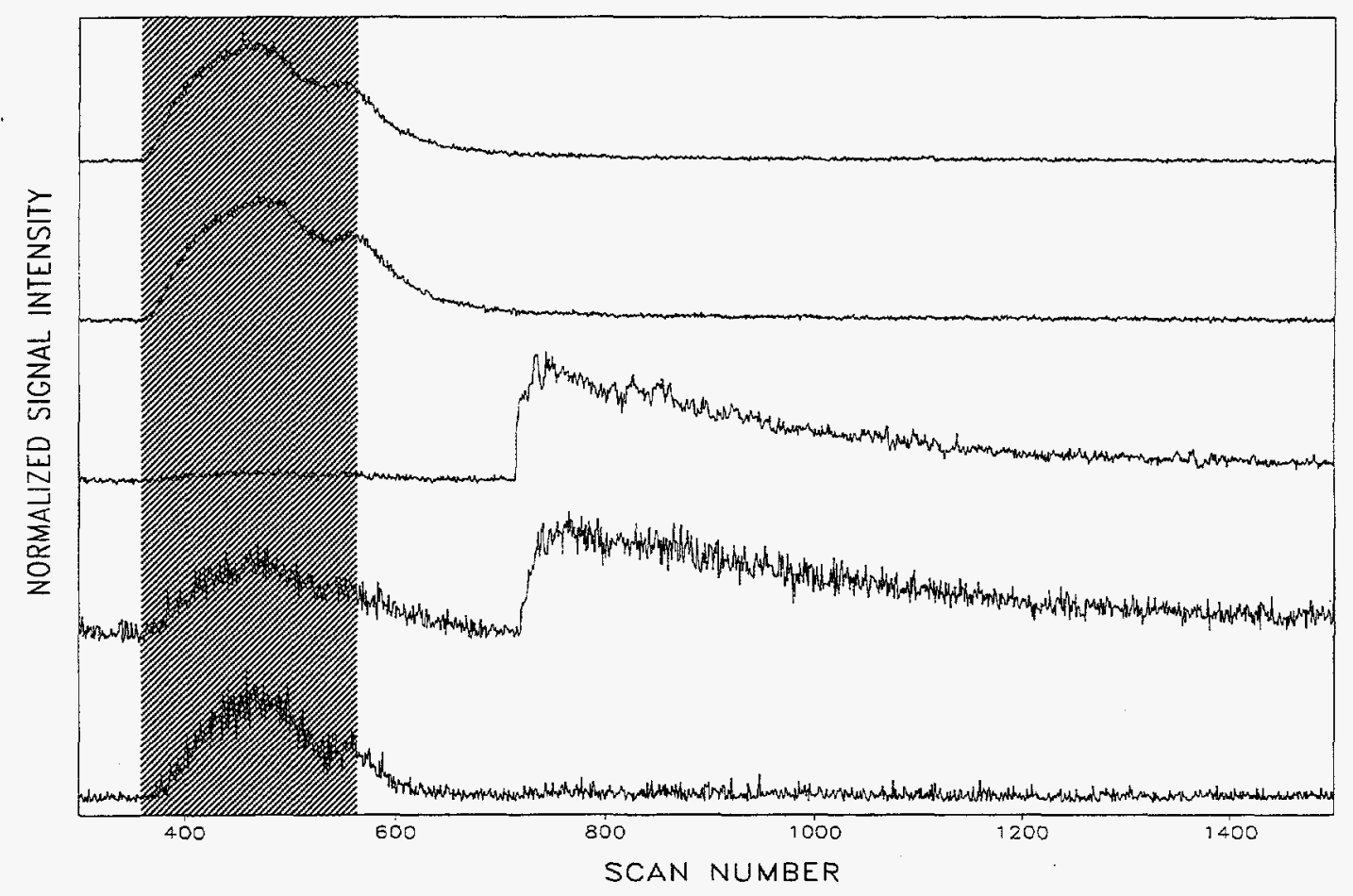

Figure 10: Selected ion plots $(\mathrm{m} / \mathrm{z} 63,65,73,89,91)$ collected during "standard" exposure experiment, P009-coated wafer (datafile L1218T03). The shaded area represents the time during which UV exposure occurred.

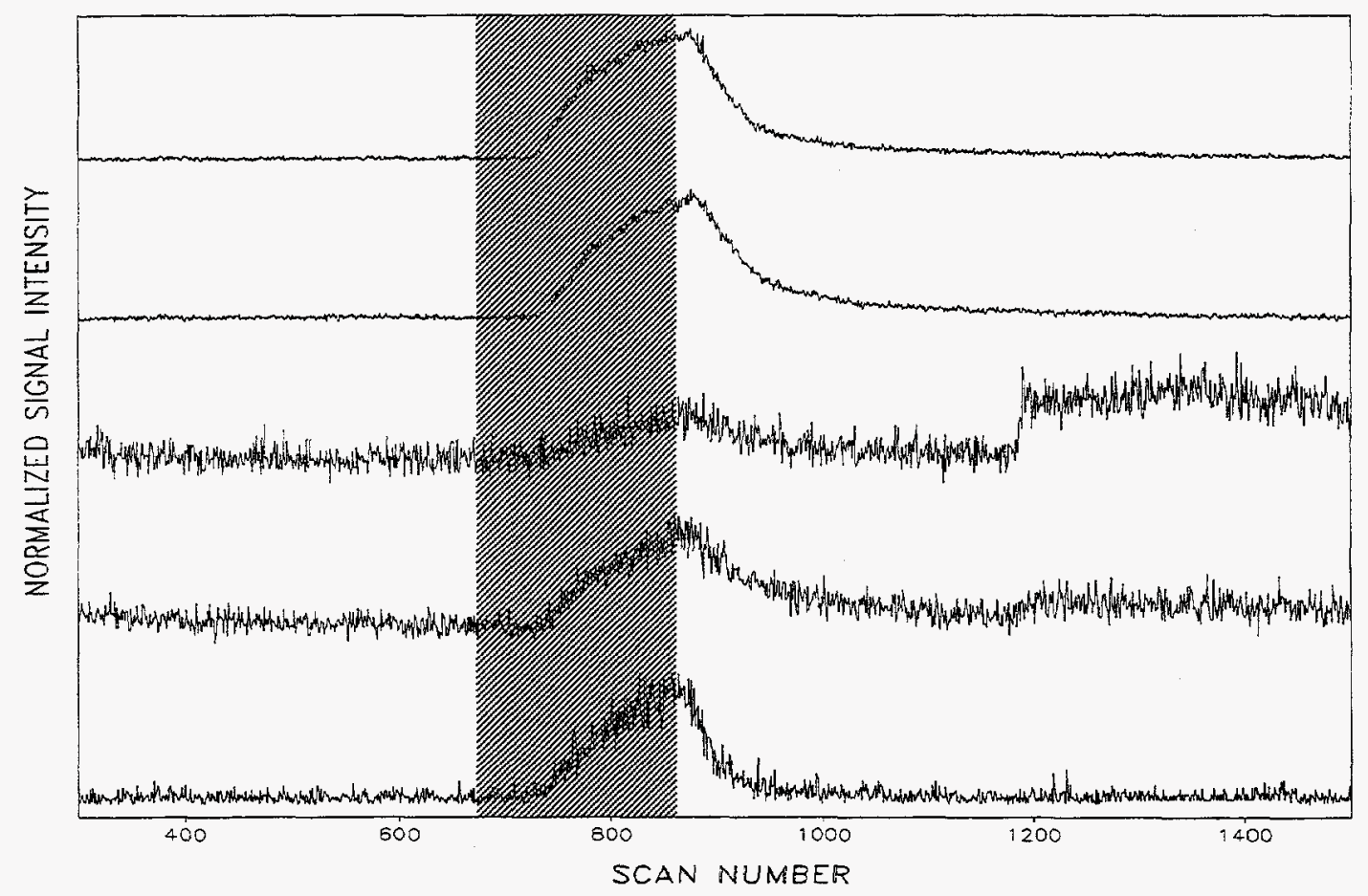

Figure 11: Selected ion plots $(\mathrm{m} / \mathrm{z} 63,65,73,89,91)$ collected during "delayed" exposure experiment, P009-coated wafer (datafile L1218T06). The shaded area represents the time during which UV exposure occurred. 


\section{Conclusions}

A remote $\mathrm{Cl} / \mathrm{MS}$ monitor detected, in-situ and real-time, species outgassed during UV exposure of four different photoresists. In addition, the $\mathrm{Cl} / \mathrm{MS}$ monitor detected differences between the photoresists with respect to the quantity, identity, and characteristics of the species outgassed. Ion signals representing the primary component (either PGMEA or ethyl lactate), as listed in the MSDS of each resist, were detected, demonstrating the capability of $\mathrm{Cl} / \mathrm{MS}$ monitoring to identify outgassed species.

Results demonstrated the ability of Cl/MS monitoring to measure the state of the wafer during processing. Increased signals as a result of UV exposure were observed and differentiation between wafers cooled for 2 minutes or 8-10 minutes was possible. A delay in the detected PGMEA signal, observed for PGMEA-based photoresists, indicates a change in the wafer status (either chemical or physical) several minutes after exposure was completed. Evaporation of some species prior to UV exposure was also observed.

The sensitivity of the $\mathrm{Cl} / \mathrm{MS}$ monitor to detect changes in the overall exposure process highlights the limitations of recreating an automated manufacturing process in the laboratory. Difficulties in controlling the humidity may have affected the signals observed in "delayed" exposure experiments. Also, in one case, a signal variation was observed due to the manual scanning methods. Variations in other factors, including photoresist thickness and scanning rate, could also have affected the results.

The results demonstrate that useful monitoring can be performed remotely with long sampling lines. This provides flexibility in the implementation of actual on-site monitoring of the automated manufacturing process, which would eliminate the added experimental uncertainties caused by the laboratory version. In addition, results obtained in an actual manufacturing setting could be correlated with other information such as device yield.

Despite the remote location, it was possible to detect signal changes in less than 15 seconds. These signals can provide insight into the chemical processes occurring on the wafer, serve as process metrics, and provide measurements useful for fault detection, failure analysis, method development, and quality control. These signals can also be utilized by tool and photoresist manufacturers for method development (i.e. processing times) and photoresist development (i.e. component evaporation from wafer, UV interactions) to ultimately improve device yield. 


\section{DISTRIBUTION}

$\begin{array}{lll}1 & \text { MS } 0343 & \text { M.R. Keenan, 1824 } \\ 20 & \text { MS 0343 } & \text { C.D. Mowry, 1824 } \\ 2 & \text { MS 0343 } & \text { S.M. Thornberg, 1824 } \\ 1 & \text { MS 0343 } & \text { S.F.A. Bender, 1824 } \\ 1 & \text { MS 0343 } & \text { M.J. Kelly, 1824 } \\ 1 & \text { MS 0755 } & \text { D.S. Blair, 6233 } \\ 1 & \text { MS 0874 } & \text { R.S. Blewer, 1305 } \\ 1 & \text { MS 0874 } & \text { R. Donovan, 1305 } \\ 1 & \text { MS 9018 } & \text { Central Technical Files, 8940-2 } \\ 2 & \text { MS 0899 } & \text { Technical Library, 4916 } \\ 2 & \text { MS 0619 } & \text { Review and Approval Desk, 12690 for DOE/OSTI } \\ 3 & \text { MS 0161 } & \text { Patent and Licensing Office, 11500 }\end{array}$

